
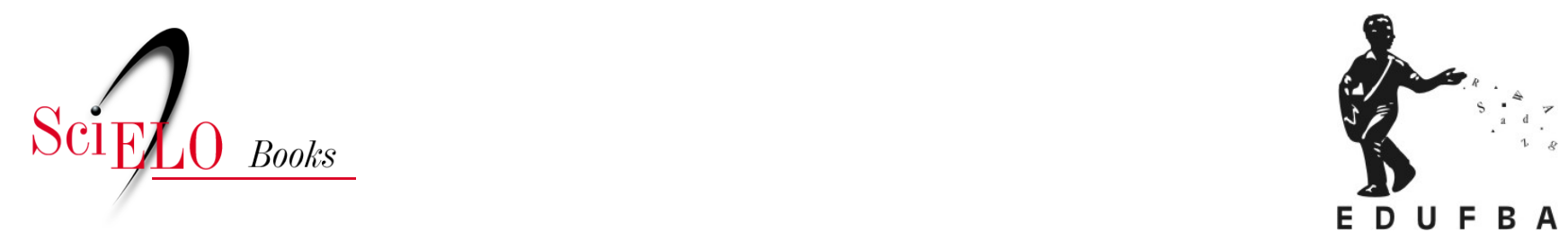

\title{
Políticas públicas para fomento científico, tecnológico e de inovação
}

\author{
Valdinéia Barreto Ferreira
}

\section{SciELO Books / SciELO Livros / SciELO Libros}

FERREIRA, V.B. Políticas públicas para fomento científico, tecnológico e de inovação. In: E-science e políticas públicas para ciência, tecnologia e inovação no Brasil [online]. Salvador: EDUFBA, 2018, pp. 31-55. ISBN: 978-85-232-1865-2. https://doi.org/10.7476/9788523218652.0004.

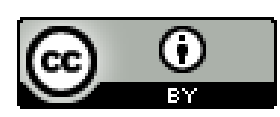

All the contents of this work, except where otherwise noted, is licensed under a Creative Commons Attribution $\underline{4.0 \text { International license. }}$

Todo o conteúdo deste trabalho, exceto quando houver ressalva, é publicado sob a licença Creative Commons Atribição 4.0.

Todo el contenido de esta obra, excepto donde se indique lo contrario, está bajo licencia de la licencia Creative Commons Reconocimento 4.0. 


\title{
POLÍTICAS PÚBLICAS PARA FOMENTO CIENTÍFICO, TECNOLÓGICO E DE INOVAÇÃO
}

\begin{abstract}
A nave espacial Terra é movida por quatro motores associados e, ao mesmo tempo, descontrolados: ciência, técnica, indústria e capitalismo (lucro). O problema está em estabelecer um controle sobre estes motores: os poderes da ciência, da técnica e da indústria devem ser controlados pela ética, que só pode impor seu controle por meio da política.
\end{abstract}

(MORIN, 2002)

O fluxo de conhecimento entre a academia e a indústria não pode se tornar uma via de mão única. Esta observação é salientada por Povoa (2008, p. 19) ao afirmar que "a existência de uma complexa relação interativa entre ciência e tecnologia faz com que o fluxo de conhecimento entre a academia e a indústria não seja uma via de sentido único". Esse autor destaca ainda a atuação de atores como universidade, institutos de pesquisa, indústria e as agências de fomento, as últimas representadas pelo sistema nacional de inovação, o que reforça a pertinência dos elementos que estruturam esse livro.

Decisões políticas são tomadas com base em avaliações que a comunidade cientifica realiza sobre a dinâmica da produção científica e tecnológica dos pesquisadores das instituições de pesquisa, universidades e empresas. O interesse por assuntos que contemplam aspectos como produtividade, qualidade da pesquisa e colaboração em CT\&I são correntemente considerados (MARICATO, 2010). 
Ao se fazer um resgate do cenário histórico e político brasileiro, especialmente a partir do século XIX, são evidenciados os primórdios do binômio C\&T com as atividades na "agricultura e mineração que receberam incentivos para a inovação e o desenvolvimento tecnológico, principalmente com o fim da escravidão em 1889." (LEMOS; CÁRIO, 2013, p. 2). A produção de trabalhos científicos e tecnológicos expressivos pode ser constatada nos trabalhos realizados por cientistas como Adolfo Lutz, Oswaldo Cruz, Roberto Landell de Moura, Vital Brazil, Alberto Santos Dumont entre outros. A Ciência brasileira "foi marcada por um crescimento lento até os anos 1980, o quadro passa a evoluir rapidamente na última década do século XX e se acelera na primeira década do século XXI." (SOCIEDADE BRASILEIRA PARA O PROGRESSO DA CIÊNCIA, 2011, p. 54).

A explicitação do componente inovação, na primeira metade do século XXI, foi um ponto marcante para as agendas estratégicas de política em C\&T, ao ponto de redefini-las como política de Ciência, Tecnologia e Inovação (CT\&I). A ação coordenada de vários atores favorece a criação da inovação e permite a formação de uma cadeia de conhecimentos. Esta temática foi introduzida no centro dos debates na área, durante a II Conferência Nacional de Ciência Tecnologia e Inovação, em 2001, mas ela estava presente em todas as experiências de reforma na década anterior. Este tripé trouxe, como força propulsora, a necessidade de expandir as fronteiras do conhecimento, agregar novidades e assegurar seu impacto na melhoria de qualidade de vida da sociedade moderna (BALBACHEVSKY, 2010; BORGES, 2011; CENTRO DE GESTÃO E ESTUDOS ESTRATÉGICOS, 2008).

O conhecimento científico é reconhecido como um vetor estratégico para a solução dos grandes problemas do mundo contemporâneo como fome, meio ambiente, energia, entre outros. Nas últimas décadas, a produção desse conhecimento no Brasil foi positiva, de acordo com os indicadores publicados pelos agentes financiadores. O que infelizmente ainda não se pode dizer dos resultados advindos da transformação dessa ciência em desenvolvimento tecnológico e inovação. Uma política de CT\&I robusta potencializará a combinação entre o conhecimento científico, tecnológico e os insumos criados pela inovação, por isso, salienta-se que essa combinação ainda precisa avançar muito. 
Os atores envolvidos nesta combinação, como as universidades e instituições de pesquisa, acolhem a Ciência ao realizarem suas práticas, ao refutarem e/ou corroborarem os pressupostos vigentes. Sem um espaço que delimite seu desenvolvimento, a técnica ocorre à medida que surgem problemas práticos que demandam resolução com motivações diversas. Como um privilégio do mundo moderno é apresentada a inovação, na medida em que se liga com o regime capitalista corrente. Ciència, Tecnologia e Inovação caracterizam um tripé próximo mas com atividades que os distingue e delimita sua atuação (SANTOS JÚNIOR, 2011).

\section{Ciência, tecnologia e inovação: um tripé de peso}

A Ciência, a Tecnologia e a Inovação, segundo Viotti e Macedo (2003, p. 45), "são elementos-chave para o crescimento, a competitividade e o desenvolvimento de empresas, indústrias, regiões e países". Por esse motivo, a busca pela compreensão e monitoramento dos processos de produção, difusão e uso de conhecimentos científicos, tecnológicos e de inovação é uma tarefa que se impõe.

As palavras ciência e tecnologia carregam concepções conceituais que as caracterizam e definem de acordo com o significado e contexto empregado. Em linhas gerais, a palavra ciência é utilizada como sinônimo de saber, conhecimento ou informação e originou-se do termo em latim scientia, o qual significa saber, conhecer, informar. Contudo, em um sentido mais restrito, refere-se a uma forma especial de conhecimento, o conhecimento científico, em contraposição a outras formas existentes (BARBIERI, 1990; CUNHA, 2012).

A palavra tecnologia tem origem no termo grego thecné; na literatura não filosófica da Grécia antiga, referia-se à esperteza, astúcia no fazer, bem como habilidade nas artes e produções. De modo geral, desde o início foi associada, ao termo latino ars artis, que significava um conjunto de regras capaz de dirigir uma atividade humana qualquer. A técnica não fazia distinção com a arte, com a ciência, nem com outro processo ou operação capaz de produzir um efeito qualquer. Em um sentido menos abrangente, significava técnica no sentido de uma arte, habilidade ou ofício, mas não uma habilidade qualquer e, sim, aquela que segue certas regras (ABBAGNANO, 2007; MORAIS, 1988; OLIVEIRA, 2010). 
O termo inovação conforme Cunha (2011, p. 453), vem do latim innnovãre, nova, novidade, conceito que adquiriu um significado e utilização de modo acentuado ao agregar-se aos termos ciência e tecnologia. Segundo Silva e Bignetti (2012, p. 2),

o conceito e as práticas de inovação têm se expandido de forma acelerada. Não apenas o termo inovação adquiriu novos significados como, também, o seu desenvolvimento e a sua aplicação ultrapassaram as fronteiras da empresa e, até, das nações.

No contexto contemporâneo, no qual predominam atividades como, parcerias entre universidade e empresa, propriedade intelectual e transferência tecnológica, o termo inovação foi inserido em uma agenda, em que a capacidade de inovar era considerada uma das mais importantes características das organizações competitivas e que buscavam obter resultados e expansão.

A Ciência se desenvolveu calcada nas diversas teorias, paradigmas e hipóteses que emergiram e/ou foram substituídos durante seu processo de produção. A refutação e/ou corroboração dos pressupostos que a fundamenta sempre fizeram parte de seu percurso de crescimento e solidificação. Conforme Silva (2002a, p. 1), "em ciência, as respostas raramente são definitivas, mas as perguntas perduram”. A Ciência se alimenta das inquietações e questionamentos oriundos da sociedade humana, procura responder 'o porquê' e não se contenta em perceber apenas o 'como' das questões. O 'porquê' caracteriza e representa problemas, objetos e recortes das disciplinas e/ou assuntos que constituem o locus em que está inserida a problemática.

Em seus primórdios, a Ciência tinha como objetivo principal entender especialmente os fenômenos da natureza e as necessidades que emanavam do homem. Com o passar do tempo, caracterizou-se tanto pela tentativa do homem em entender e explicar racionalmente a natureza quanto por formular leis que permitissem, em última instância, sua ação. Em razão das limitações existentes e peculiares ao seu início, a atividade científica era desenvolvida de modo lento e seus pesquisadores possuíam uma atuação isolada (ANDERY et al., 2003; MEADOWS, 1999; MORAIS, 1988; POPPER, 2006; REZENDE, 2010). 
Nos primórdios, "os rudimentos de tecnologia surgem como as primeiras ferramentas, manipuladas a partir do ferro e do cobre. Tais ferramentas aumentavam a probabilidade de sobrevivência em uma natureza altamente hostil." (MEDEIROS, 2012, p. 44). Contudo, já incluía um aspecto teórico em seu sentido, por ser usada para indicar capacidade de se justificar certo procedimento, isto é, o porquê da eficiência de determinado procedimento.

Com raízes na idade antiga, a Ciência como a atividade que conhecemos hoje, a partir da época do Renascimento na Europa começou a ter nova forma e desenhar uma Ciência moderna. A discussão acerca da controversa relação entre a Ciência e a Tecnologia abarca correntes com posicionamentos que as visualizam em alguns momentos unidas e originárias de uma mesma matriz histórica e em outros como desdobramentos uma da outra. Entretanto, é inegável que na revolução galileica, ${ }^{1}$ a Ciência e a Técnica conseguiram unir-se, pelo menos na visão da corrente hegemônica da maioria dos historiadores que interpretavam o surgimento da tecnologia como um desdobramento da Ciência moderna. Isso foi decisivo para o início da Ciência aplicada, da maneira como é entendida na atualidade (MORAIS, 1988; OLIVEIRA, 2010).

A Tecnologia era calcada apenas em bases empíricas e desenvolvida por meio de tentativas, o desenvolvimento da Ciência moderna veio lhe trazer bases sólidas e um campo de observação de fenômenos muito mais vasto. A concepção da inter-relação entre Ciência e Tecnologia somente nos últimos $100 \mathrm{a}$ 200 anos veio a ser percebida de fato (REZENDE, 2010). Saberes de importância fundamental "na decisão dos estilos de vida, da educação, de cultura, em suma de uma concepção de mundo" é o que Apaza Yanarico (2011, p. 99) considera a Ciência e a Tecnologia, ou a Tecnociência.

A socialização exigida pela Ciência, a transforma em um produto consciente da humanidade com uma execução rotineira e colaborativa. A abrangência desse campo do conhecimento abarca uma gama de expressões, instrumentos,

1 Revolução galileica - revolução atribuída ao físico Galileu Galilei (1564-1642) e considerada como o momento simbólico do nascimento do experimentalismo científico. Em 1590, Galileu resolve pôr a prova os ensinamentos de Aristóteles, baseado na premissa de que um pensamento pode ser perfeitamente lógico e enquadrado no bom senso, sem que necessariamente seja verdadeiro. Ele propôs que valorizássemos os sentidos, utilizássemos nossos recursos físicos como meios autênticos de veiculação do conhecimento e, desse modo, ele ultrapassou os limites da Ciência transformando-se em uma nova atitude perante a verdade (MORAIS, 1988). 
pessoas, instituições e “coisas” que são intrínsecas ao seu fazer. A literatura sobre a Ciência é muito fértil e, como o próprio Latour (1997, p. 19) qualifica, chega a ser "gigantesca". Um trecho do pensamento de Ziman sobre a Ciência resgata a essência e fundamentos sob os quais ela está assentada. Uma declaração coerente e atual como se constata na citação a seguir.

A Ciência é uma parte importante do acervo de nossas mentes; seus produtos formam os acessórios à nossa volta [...]. A Ciência é, inegavelmente, um produto consciente da humanidade, com suas origens históricas bem documentadas, um escopo e um conteúdo bem definidos; além do mais, conta com praticantes e expoentes reconhecidamente profissionais. [...] A Ciência [...] é precisa, metódica, acadêmica, lógica e prática. [...] Ciência não significa simplesmente conhecimentos ou informações publicados. [...] O conhecimento científico é mais do que isso. Seus fatos e teorias têm de passar por um crivo, por uma fase de análises, críticas e de provas, realizadas por outros indivíduos competentes e desinteressados, os quais deverão determinar se eles são bastante convincentes para que possam ser universalmente aceitos. O objetivo da Ciência não é apenas adquirir informação, nem enunciar postulados indiscutíveis, sua meta é alcançar um consenso de opinião racional que abranja o mais vasto campo possível (ZIMAN, 1979, p. 17-24).

O papel desempenhado pela tecnologia na concepção de Kuhn (2011, p. 36) é considerado vital para o surgimento "de novas ciências, já que os ofícios são uma fonte facilmente acessível de fatos que não poderiam ter sido descobertos casualmente."

A compreensão da natureza da Ciência e da Tecnologia sempre demandou uma observação apurada do comportamento dos seus atores e da atividade em torno da qual eles empreendem seus esforços, a prática científica e tecnológica. A comunidade científica constrói o conhecimento científico e devolve-o à sociedade como uma resposta aos questionamentos dessa oriundos. Neste ambiente, o processo de produção do conhecimento acontece e é retroalimentado, transformando e sendo transformado, afetando a sociedade na mesma medida em que é por ela afetado. A pesquisa científica como salienta Ziman (1979, p. 25) "é 
uma atividade social. [...] Para bem compreendermos a natureza da Ciência precisamos observar a maneira como os cientistas se comportam uns com os outros, como se organizam e como transmitem as informações entre si." Com um olhar crítico e inovador, Latour (2012, p. 31, grifo do autor) reforça essa assertiva e renova a necessidade de seguir os atores do processo ao dizer:

[...] cumpre 'seguir os próprios atores', ou seja, tentar entender suas inovações frequentemente bizarras, a fim de descobrir o que a existência coletiva se tornou em suas mãos, que métodos elaboraram para sua adequação, quais definições esclareciam melhor as novas associações que eles se viram forçados a estabelecer.

O entrelaçamento dos atores com as coisas tornou-se o fio condutor dessa visão renovada de Ciência e Tecnologia e conforme indica Souza e Sales Júnior (2012, p. 14) "seguir os atores nesse caso é segui-los em seu entrelaçamento com as coisas, pois sim as coisas também agem, elas podem autorizar, permitir, proporcionar, encorajar, sugerir, influenciar, bloquear, dificultar etc."

A passagem do tempo evidencia as mudanças ocorridas na sociedade e seus desdobramentos na política, economia e cultura. Nesse contexto, e especialmente na economia do conhecimento, identificam-se os agentes do processo de construção do conhecimento e as transformações por que passaram e passam tais como: as ferramentas, tecnologias e artefatos utilizados e produzidos; o tratamento dos dados brutos e da informação científica e tecnológica; a prática colaborativa; a comunicação e divulgação científica; as formas de publicação e avaliação; o reuso; a captura; a curadoria; e análise desses produtos; enfim, as "coisas" que se entrelaçam com os atores e que também se transformam em atores, ou melhor, em actantes ${ }^{2}$ e culminam com a transformação da sociedade em um coletivo que a todos agrega.

A criação das primeiras instituições de caráter técnico e científico no Brasil ocorreu a partir de 1808, com a instalação da Família Real Portuguesa no país (LEMOS; CÁRIO, 2013). O papel das instituições universitárias, institutos e centros de pesquisa foram de fundamental importância para o preparo de

2 No "inglês, a palavra 'actor' (ator) se limita a humanos, utilizamos muitas vezes 'actante' (atuante), termo tomado da semiótica, para incluir não humanos na definição." (LATOUR, 2001, p. 346). 
um ambiente propício ao nascimento da Ciência brasileira e ao surgimento da pesquisa tecnológica no país. Rezende (2010, p. 13) destaca esse momento ao relatar que:

O desenvolvimento da Ciência e Tecnologia no Brasil exigiu a criação de um amplo conjunto de instituições e de um novo estatuto para o ensino universitário. Foi necessário construir órgãos federais e estaduais voltados para o financiamento da pesquisa; foi reformado o regime de trabalho nas universidades, incorporando o tempo integral para os docentes; foram constituídas muitas universidades e centros de pesquisa; foi gradualmente afirmando-se uma cultura que incorporava a Ciência e a Tecnologia como instrumentos na agenda das políticas públicas, tornando esse binômio partícipe no enfrentamento das questões sociais do país.

O mundo ficou mais alerta para questões como segurança, economia e saúde tornando-se um solo frutífero para o desenvolvimento de pesquisas científicas e tecnológicas depois dos reflexos do pós-segunda-guerra. O despertar para a real importância da Ciência e Tecnologia (C\&T), no Brasil, é recente para um país que busca o desenvolvimento social e econômico da sua sociedade. A implementação de políticas para este fim é uma necessidade latente.

O desejo de inserção entre as grandes potências mundiais, além da diminuição da dependência, tecnológica impulsionou a compreensão de que C\&T são motores para o crescimento, competitividade e desenvolvimento de um país. Para a conquista desses indicadores, a inserção da C\&T em sua agenda política tornou-se imprescindível. "A base científica e tecnológica do país precisa ser ampliada, sobretudo para impulsionar a competitividade das empresas brasileiras e contribuir para a criação de um parque industrial sólido nos setores de alta e média-alta intensidade tecnológica ${ }^{3}$ (SOCIEDADE BRASILEIRA PARA O PROGRESSO DA CIÊNCIA, 2011).

O momento seguinte à segunda guerra mundial foi marcante, especialmente para o conjunto de inovações tecnológicas que tiveram como exponenciais

3 Classificação da Organisation for Economic Co-operation and Development (OCDE ) (OCDE, 2009). 
as tecnologias de informação e comunicação. O exame das questões que envolveram essas mudanças pode ser realizado utilizando-se óticas distintas, as quais podem ser identificadas como correntes teóricas que fundamentaram e construíram o alicerce para as análises realizadas. Recorrendo aos fundamentos construídos pelos "gigantes" predecessores, os teóricos contemporâneos que representam estas correntes nem sempre hegemônicas, defenderam pressupostos que em alguns aspectos possuíam interseções em alguns aspectos, mas que eram diametralmente opostos em outros.

No conjunto que representa essas correntes de pensamento estão inseridos autores como Manuel Castells, Michel Foucault, Howard Becker, Pierre Bourdieu, Pierre Levy e Bruno Latour, para citar alguns, um referencial teórico abrangente que necessitaria de muito fôlego para um resgate adequado. Entretanto, por não ser esta a intenção precípua da pesquisa desenvolvida, optou-se por ater-se a um recorte específico dos estudos da moderna Sociologia da Ciência, a Teoria Ator-Rede. Acredita-se que ela representa um referencial adequado para o objetivo pretendido na pesquisa e se enquadra no escopo em que está inserido o estudo que foi desenvolvido.

Esse escopo que contempla como elementos estruturantes e norteadores como pontuado anteriormente: práticas e redes colaborativas para inovação; e-Science e políticas públicas para o fomento científico e tecnológico. A ANT engloba uma abordagem que representa um conjunto teórico, abrangente e orgânico que não obstante sua rica contribuição, "têm sua unidade no esforço de compreender objetos de estudo cada vez mais destacáveis na sociedade contemporânea, a saber, a ciência e a tecnologia." (PREMEBIDA et al., 2011, p. 23).

\section{Sistema Nacional de Ciência, Tecnologia e Inovação}

À criação do Conselho Nacional de Desenvolvimento Científico e Tecnológico (CNPq), e da Coordenação de Aperfeiçoamento de Pessoal de Nível Superior (Capes) é atribuído o início da institucionalização da Ciência brasileira. O CNPq como responsável pelo fomento à pesquisa e a Capes incumbida do apoio à for-

4 Refere-se à metáfora "gigante", utilizada por Isaac Newton ao atribuir aos inúmeros teóricos predecessores a base para a construção dos pressupostos da Ciência, a qual é resgatada por Ziman (1979). 
mação de recursos humanos e, até se chegar a esse patamar, um longo percurso se trilhou no país. Antes da criação desses órgãos o desenvolvimento científico passou por muitas dificuldades (OTAVIANO, 2011).

Durante o processo de consolidação da C\&T no país, ocorreu certa descontinuidade, a qual perpassou regimes políticos, programas e planos governamentais. Em alguns casos, privilegiavam políticas de governo em detrimento de políticas de estado e, em outros, reconheciam o real valor desse binômio para o desenvolvimento do país e investiam criando instrumentos para sua implementação. O resgate da história e política brasileira voltadas para o desenvolvimento da C\&T é apresentado por Valentim (2002), o qual pontua as ações dos governos brasileiros de Getúlio Vargas a José Sarney. Esse referencial é pertinente como base para o entendimento da atual conjuntura que cerca o assunto.

O processo foi marcado por avanços e recuos e a criação de algumas instituições foi significativa para a o desenvolvimento de um Sistema Nacional de Ciência e Tecnologia, mais acentuado durante as décadas de 1960, 1970 e 1980. Destacam-se, em síntese apresentada a seguir, algumas instituições que marcaram este percurso inicial e foram fundamentais para a criação de uma infraestrutura acadêmica e a implantação de políticas para a C\&T:

- a Sociedade Brasileira para o Progresso da Ciência (SBPC), criada em 1948;

- o Centro Brasileiro de Pesquisas Físicas (CBPF), em 1949;

- o Instituto Tecnológico da Aeronáutica (ITA), em 1950;

- o Centro Tecnológico de Aeronáutica (CTA), em 1950;

- o Conselho Nacional Pesquisa, em 1951, transformado em CNPq, em 1974. O propósito inicial da criação desse conselho foi equiparar o Brasil a outras nações desenvolvidas, sobretudo nas questões relacionadas à pesquisa e energia nuclear;

- a Companhia Nacional de Aperfeiçoamento de Pessoal de Nível Superior, em 1951, posteriormente designada de Capes, com o objetivo de qualificar recursos humanos, em atividades científicas e técnicas;

- a fundação da Financiadora de Estudos e Projetos (Finep), em 1967, com o objetivo de fornecer fomento para o desenvolvimento de tecnologia e apoio de sua utilização pela sociedade; 
- a implantação do Ministério da Ciência e Tecnologia (MCT) $)^{5}$ em 1985 que absorveu em sua estrutura a Finep, o CNPq e suas estruturas de pesquisa; e

- o Fundo Nacional de Desenvolvimento Científico e Tecnológico (FNDCT) atuando desde 1985 (LEMOS; CÁRIO, 2013; OTAVIANO, 2011; REZENDE, 2010; VALENTIM, 2002).

Tornou-se evidente a necessidade do desenvolvimento de infraestrutura que permitisse a construção de bases sólidas para resolver os problemas estruturais da sociedade. Pontuam-se como desafios constantes para esse processo as novas fontes de financiamento à pesquisa e ao desenvolvimento tecnológico; os arranjos institucionais que começam a emergir; e os atores que se organizam em diferentes fóruns, movimentos e etapas do processo de criação, desenvolvimento e implementação de políticas para o setor (CENTRO DE GESTÃO E ESTUDOS ESTRATÉGICOS, 2008).

A interferência do tripé CT\&I é cada vez mais percebida. Os investimentos são pontuais, em uma infraestrutura adequada para que o Brasil conquiste a tão almejada igualdade de desenvolvimento para sua sociedade e para que também possa se igualar aos países ditos desenvolvidos.

Em novembro de 2007 foi anunciado o Plano de Ação em Ciência, Tecnologia e Inovação 2007-2010 (PACTI), um importante instrumento para orientar as ações do Estado voltadas para a implementação de uma infraestrutura robusta para o desenvolvimento almejado na Ciência, Tecnologia e Inovação do país. O plano possui metas ambiciosas que dependem, para o seu cumprimento, de atuação articulada e uma gestão compartilhada entre os atores envolvidos. As prioridades do PACTI, segundo o MEC, são norteadas pelos quatro eixos estratégicos da Política Nacional de CT\&I, a saber:

- expansão e consolidação do Sistema Nacional de Ciência, Tecnologia e Inovação;

- promoção da inovação tecnológica nas empresas;

5 O Ministério de Ciência Tecnologia (MCT) mudou a nomenclatura para Ministério da Ciência, Tecnologia e Inovação (MCTI) em 02 de agosto de 2011. A mudança encontra-se na exposição de motivos da Medida Provisória 541, de 2 de agosto de 2011, publicada no Diário Oficial da União de 03 de agosto de 2011 (BRASIL, 2011). 
- pesquisa, desenvolvimento e inovação em áreas estratégicas; e

- ciência, tecnologia e inovação para o desenvolvimento social (BRASIL, 2010, p. 9).

Apresenta-se a seguir, o modelo atual do Sistema Nacional de Ciência, Tecnologia e Inovação (SNCT\&I), com a intenção de identificar os agentes responsáveis pela alocação de recursos, financiamento de projetos e capacitação dos recursos humanos inseridos na pirâmide em que ele é apresentado. Consequentemente, identificam-se também, os agentes responsáveis pela manutenção da infraestrutura de $e$-Science no Brasil e sua interferência na CT\&I nacional.

Figura 4 - Órgãos executores do Sistema Nacional de Ciência Tecnologia e Inovação

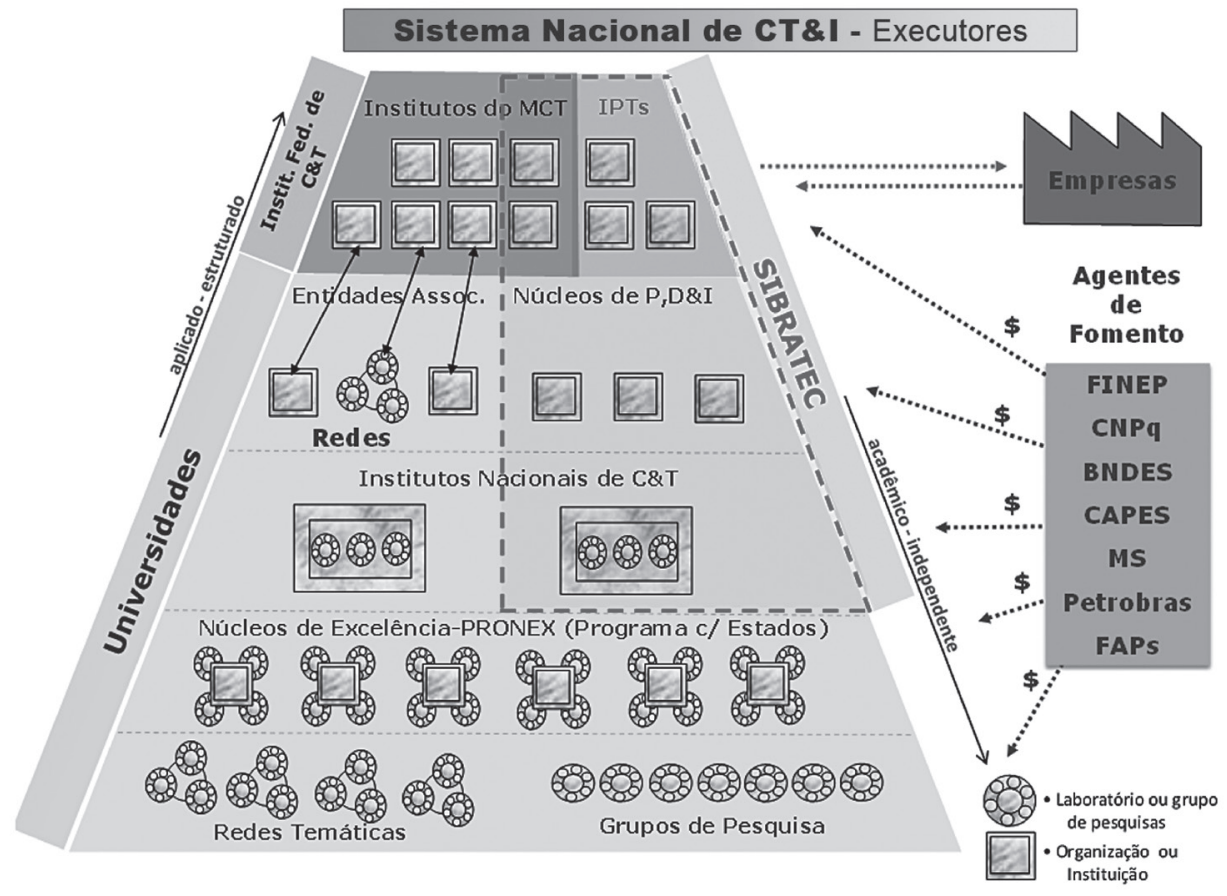

Fonte: Adaptado de SBPC (2011, p. 63).

O modelo do SNCT\&I apresentado na Figura 4, representa a infraestrutura atual de pesquisa no país e foi elaborado pelo Ministério de Ciência e 
Tecnologia (MCT). Sua composição engloba 12 ministérios, 20 unidades de pesquisa, 28 universidades e 25 fundações de amparo à pesquisa estadual (OTAVIANO, 2011). Acrescentam-se ainda a esta composição as diversas empresas públicas e privadas, os agentes de fomentos como a Finep, o CNPq, o Banco Nacional de Desenvolvimento Econômico e Social (BNDES), a Capes, grupos de pesquisa e laboratórios inseridos no âmbito das universidades e institutos de pesquisa.

Uma infraestrutura para pesquisa que se consolida cada vez mais em busca da manutenção de uma constância em suas frentes de atuação além das áreas estratégicas para o desenvolvimento do país. Para tanto, contudo, são necessários investimentos cada vez mais robustos em educação, recursos humanos qualificados e financiamento de projetos nas diversas áreas do conhecimento.

A implantação das diversas modalidades de financiamentos concedidas pelo BNDES, Finep, FNDCT entre outros, foi fundamental para o apoio à infraestrutura de C\&T e aos projetos de pesquisa. Os resultados não tardaram a chegar e mostraram os lucros econômicos gerados com os investimentos realizados, apesar do país ainda não ter alcançado o índice desejado mesmo após três décadas de implantação. Conforme acentua Octaviano (2011), o SNCT\&I "ainda apresenta déficits e alguns pontos fracos, pois pode ser considerado recente, se for comparado ao de outros países desenvolvidos."

As dificuldades vivenciadas pelo MCT foram decisivas para a criação e extinção de instrumentos de financiamento caracterizados como programas ou projetos. Conforme o Centro de Gestão e Estudos Estratégicos (2008, p. 10) os "projetos são definidos como recursos atribuídos a grupos ou indivíduos para a realização de uma atividade de pesquisa limitada na sua abrangência, orçamento e tempo, normalmente pela submissão de uma proposta de pesquisa." Pontua-se a seguir, alguns exemplos de programas implementados e decisivos para a manutenção favorável de uma infraestrutura científica, tecnológica e de inovação para o país.

- o Programa de Apoio do Desenvolvimento Científico e Tecnológico (PADCT), o qual vigorou de 1985 a 1998 e utilizava recursos de empréstimos do Banco Mundial (Bird) e contrapartidas do Tesouro Nacional; 
- o Programa de Apoio a Núcleos de Excelência (Pronex), cujo objetivo era proporcionar apoio financeiro continuado apenas aos grupos de pesquisa de alta competência e eram articulados em redes temáticas;

- o Programa Institutos do Milênio que substituiu o Pronex e visava promover a formação de redes de pesquisa em todo território nacional. Esse programa buscava a excelência científica e tecnológica e o fortalecimento de grupos de pesquisa em qualquer área do conhecimento, assim como as definidas como estratégicas;

- o Programa Jovens Pesquisadores, que apoia projetos de pesquisa e de instalação de infraestrutura;

- o Programa Primeiros Projetos, cujo objetivo é apoiar a aquisição, instalação, modernização ou recuperação da infraestrutura de pesquisa nas instituições públicas de ensino e pesquisa;

- e o Programa Institutos Nacionais de Ciência e Tecnologia (INCTs), criado em 2008 e analisado na pesquisa, a qual derivou esse livro, como veremos com mais detalhadamente no decorrer do estudo, substituiu os Institutos do Milênio (REZENDE, 2010).

A Política de Ciência, Tecnologia e Inovação (PCT\&I) atual possui características do ponto de vista de alocação de recursos que destaca o financiamento a projetos, ao lado do financiamento direto a universidades e a outras instituições de pesquisa. Do ponto de vista de conteúdo, busca atender aos seguintes objetivos: a) fortalecimento e ampliação de uma base de conhecimento ampla e socialmente relevante; b) fortalecimento da interação entre os diversos atores do sistema nacional de inovação; c) descentralização das atividades de produção e uso do conhecimento, desenvolvimento regional e local nas políticas de CT\&I (CENTRO DE GESTÃO E ESTUDOS ESTRATÉGICOS, 2008).

Os maciços investimentos resultaram em um avanço significativo da Ciência nacional, mas conforme destaca Borges (2011, p. 182) em seu diagrama apresentado na Figura 5, é necessária ainda uma atuação de maneira estrutural e estratégica que contemple a tecnologia e a inovação no contexto nacional como uma forma de equilibrar o desenvolvimento do tripé CT\&I. 
Figura 5 - Caracterização da CT\&I no Brasil: (A) vigente (B) desejada
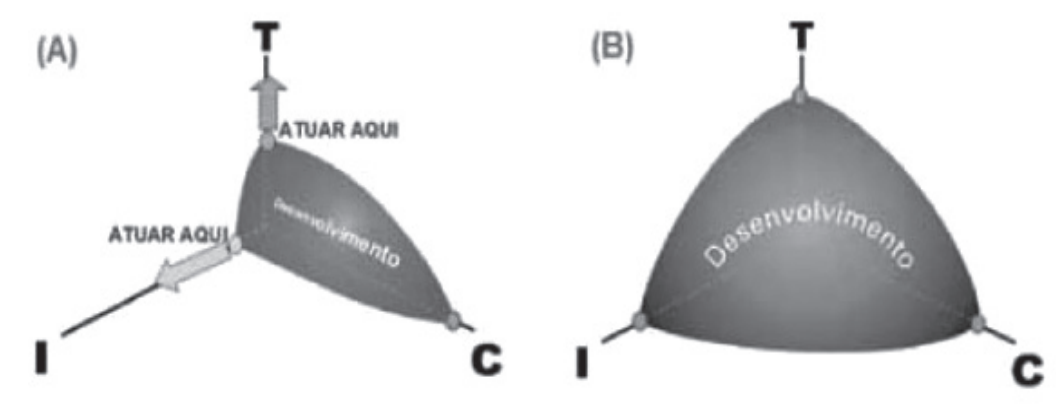

Fonte: Adaptado de Borges (2011, p. 182).

A busca de soluções para mudar a realidade apresentada é constante entre os responsáveis pelo SNCT\&I. Desse modo, é lançado o Programa Institutos Nacionais de C\&T, instituído pela Portaria MCT n ${ }^{\circ}$ 429, de 17 de julho de 2008 (BRASIL, 2008), em substituição ao Programa Institutos do Milênio. O programa que congrega redes cooperativas de pesquisa formadas em torno de um tema comum e tratadas de forma multidisciplinar e os INCTs foram selecionados como locus para o estudo em desenvolvimento. Essa escolha foi pautada, na identificação de semelhanças entre os objetivos e características desses institutos e a infraestrutura de institutos e/ou fundações que acolhem projetos de e-Science desenvolvidos em outros países.

A próxima seção se encarregou de introduzir os detalhes do Programa Institutos Nacionais de Ciência e Tecnologia, a política pública que caracteriza os INCTs e é foco de análise para a e-Science e as práticas colaborativas desenvolvidas por seus pesquisadores.

\section{Programa Institutos Nacionais de Ciência e Tecnologia}

Criado pela Portaria MCT n ${ }^{\circ}$ 429, de 17 de julho de 2008 (BRASIL, 2008), o Programa Institutos Nacionais de Ciência e Tecnologia deveria ocupar uma posição estratégica no SNCT\&I. Ao assinar os convênios para efetivação do Programa que daria início aos INCTs, o então ministro da Ciência e Tecnologia, 
Sergio Rezende, que respondeu pela pasta de julho de 2005 a dezembro de 2010, o considerou um arranjo inovador.

Uma parceria inicial entre o Ministério de Ciência e Tecnologia (MCT), representado pela FNDCT e CNPq; o Ministério de Educação e Cultura (MEC), representado pela Capes; e o Ministério da Saúde (MS), pela Secretaria de Ciência Tecnologia e Insumos Estratégicos (SCTIE) e as Fundações de Amparo à Pesquisa (FAPs): Fundação de Amparo à Pesquisa do Estado de Minas Gerais (FAPEMIG); Fundação Carlos Chagas de Amparo à Pesquisa do Estado do Rio de Janeiro (FAPERJ); e a Fundação de Amparo à Pesquisa do Estado e São Paulo (FAPESP).

Posteriormente somaram-se as parcerias do Ministério do Desenvolvimento, Indústria e Comércio Exterior (MDIC), por meio do BNDES; do Ministério de Minas e Energia (MME), por intermédio da Petrobrás e outras entidades federais e estaduais. Dessa forma personificaram não um programa de uma entidade ou de governo, mas um programa de um país. (BRASIL, 2008; INCT, 2008). O Portal Brasileiro de Ciência e Tecnologia (2013) define os INCTs e destaca sua abrangência, características e objetivos conforme é apresentado a seguir:

Os Institutos Nacionais de Ciência e Tecnologia ou INCTs são centros de pesquisa brasileiros que abrangem todo o território nacional, sendo fomentados por verbas públicas e caracterizados pelo alto padrão de pesquisa científica realizada. $\mathrm{O}$ objetivo desses centros é contribuir para o desenvolvimento da pesquisa e criar patentes para o país, promovendo uma sinergia entre grupos de pesquisadores de diferentes instituições e áreas do conhecimento (PORTAL, 2013).

O Programa Institutos Nacionais de Ciência e Tecnologia foi considerado por autores como Rezende (2010) e Borges (2011) como o maior programa da história do CNPq e um exemplo de sucesso e visava em sua primeira edição:

- mobilizar e agregar, de forma articulada com atuação em redes, os melhores grupos de pesquisa em áreas de fronteira da ciência e em áreas estratégicas para o desenvolvimento sustentável do País, como definidas no PACTI; 
- impulsionar a pesquisa científica básica e fundamental competitiva internacionalmente;

- desenvolver pesquisa científica e tecnológica de ponta associada a aplicações, promovendo a inovação e o espírito empreendedor, em estreita articulação com empresas inovadoras, nas áreas do Sistema Brasileiro de Tecnologia (Sibratec);

- promover o avanço da competência nacional em sua área de atuação, criando para tanto ambientes atraentes e estimulantes para alunos talentosos de diversos níveis do ensino médio ao pós-graduado, e responsabilizando-se diretamente pela formação de jovens pesquisadores. Os Institutos Nacionais devem ainda estabelecer programas que contribuam para a melhoria do ensino de ciências e com a difusão da ciência para o cidadão comum;

- apoiar a instalação e o funcionamento de laboratórios em instituições de ensino e pesquisa e empresas, em temas de fronteira da ciência e da tecnologia, promovendo a competitividade internacional do País, a melhor distribuição nacional da pesquisa científico-tecnológica, e a qualificação do País em áreas prioritárias para o seu desenvolvimento regional e nacional (PROGRAMA..., 2008, p. 3).

A iniciativa possui um conjunto de agentes imbuídos do propósito de reunir grupos de pesquisadores vinculados às universidades e instituições científicas de forma multicêntrica, cujo funcionamento ficou sob a coordenação de uma instituição sede, o MCT/CNPq. Quando foi lançado em 2008, o Programa selecionou 122 INCTs, os quais congregavam os melhores grupos de pesquisa em áreas de fronteira da ciência e em áreas estratégicas para o desenvolvimento do país (CNPq, 2008).

De acordo com os dados levantados nos sítios dos INCTs e notícias veiculadas pelas agências de fomento como a FAPESP, foram selecionados 125 - 122 aprovados pelo Edital 15/2008 e três aprovados pelo Edital 71/2010 (CNPq, 2008; 2010). No Quadro 1, apresenta-se o total dos INCTs e sua inserção nas oito áreas consideradas estratégicas pelo PACTI 2007-2010, para a Ciência, Tecnologia e Inovação, além do total de pesquisadores levantados.

Esse quadro é fruto do primeiro levantamento realizado a partir de dezembro de 2013 até dezembro de 2014, período que compreendeu a coleta inicial dos dados empíricos da pesquisa, a qual derivou esse livro. Esse levantamento 
foi realizado nos sítios individuais dos institutos (INSTITUTO NACIONAL DE CIÊNCIA E TECNOLOGIA, 2014a; 2014b; 2014c; 2014d; 2014e; 2014f); no sítio oficial do CNPq (2013a; 2013b; 2013c) e Portal Brasileiro de Ciência e Tecnologia (PORTAL, 2013). Foram identificados 125 INCTs e 7395 pesquisadores e as atividades realizadas nesses INCTs estão inseridas nas oito áreas estratégicas para a CT\&I, a seguir representadas.

Quadro 1 - INCTs e áreas estratégicas para a CT\&I

\begin{tabular}{|c|l|c|c|}
\hline N. & ÁREAS ESTRATÉGICAS PARA A CT\&I & INCTs & N $^{\circ}$ DE PESQUISADORES \\
\hline 1 & Ciências Agrárias e Agronegócio & 12 & 598 \\
\hline 2 & Energia & 10 & 455 \\
\hline 3 & Engenharia e Tecnologia da Informação & 12 & 734 \\
\hline 4 & Exatas e Naturais & 11 & 555 \\
\hline 5 & Ciências Humanas e Sociais Aplicadas & 10 & 884 \\
\hline 6 & Ecologia e Meio Ambiente & 21 & 1066 \\
\hline 7 & Nanotecnologia & 10 & 855 \\
\hline 8 & Saúde & 39 & 2248 \\
\hline TOTAL & & 125 & 7395 \\
\hline
\end{tabular}

Fonte: Elaborado pela autora.

As características essenciais do Programa dos Institutos Nacionais de Ciência e Tecnologia são:

- a mobilização e agregação dos melhores grupos de pesquisa, de forma articulada em redes;

- o desenvolvimento de programa de pesquisa científica e/ou tecnológica bem definido e estruturado que permita avanços científicos substanciais ou desenvolvimento tecnológico inovador;

- a atuação em áreas estratégicas ou em áreas da fronteira da ciência;

- forte interação com o sistema produtivo e com a sociedade;

- a promoção de pesquisa competitiva e relevante para o país; e 
- a criação de ambiente atraente e estimulante para alunos talentosos de diversos níveis, do ensino médio a pós-graduação, responsabilizando-se pela formação de jovens pesquisadores (REGULAMENTO..., 2008).

O esforço colaborativo estava presente nas instituições e empresas associadas que compuseram o projeto e tornou-se visível a partir da materialização das ações por meio dos recursos financeiros empreendidos. Os recursos iniciais previstos totalizaram R $\$ 275$ milhões, em três anos com a participação estimada de 45 INCTs, recursos esses oriundos do CNPq e FNDCT representando 62,07\% do capital empreendido para alavancar o projeto.

Em virtude da participação acordada com as FAPs dos estados da região sudeste, cerca de R $\$ 135$ milhões foram aportados adicionalmente para aplicações nos respectivos estados, o que permitiu o apoio a cerca de 20 propostas adicionais. A Capes participou com recursos estimados em $\mathrm{R} \$ 30$ milhões representados por bolsas de diferentes modalidades. O financiamento de outras fontes não foi definido no Edital n ${ }^{\circ}$ 15/2008. A Tabela 1, representa o montante inicial investido para a implementação do Programa Instituto Nacionais de Ciência e Tecnologia.

Tabela 1 - Recursos financeiros - Implementação do Programa INCTs

\begin{tabular}{c|c|c|c|c|c}
\hline \multicolumn{7}{c}{ RECURSOS FINANCEIROS (R\$ milhões) } \\
\hline FONTE & 2008 & 2009 & 2010 & TOTAL & $\%$ \\
\hline CNPq & 30.000 .000 & 40.000 .000 & 40.000 .000 & 110.000 .000 & 25,29 \\
\hline FNDCT & 40.000 .000 & 60.000 .000 & 60.000 .000 & 160.000 .000 & 36,78 \\
\hline CAPES & 30.000 .000 & - & - & 30.000 .000 & 6,90 \\
\hline FAPEMIG & 30.000 .000 & - & - & 30.000 .000 & 6,90 \\
\hline FAPERJ & 30.000 .000 & - & - & 30.000 .000 & 6,90 \\
\hline FAPESP & 75.000 .000 & - & - & 75.000 .000 & 17,24 \\
\hline TOTAL & 235.000 .000 & 100.000 .000 & 100.000 .000 & 275.000 .000 & 100 \\
\hline
\end{tabular}

Fonte: Adaptado do CNPq (2008).

A possibilidade de aumento do número dos INCTs era viável em virtude do aporte de recursos de outras entidades federais ou estaduais como, os "Ministé- 
rios da Saúde e da Educação, BNDES e Petrobrás, além de empresas privadas.” (PROGRAMA..., 2008, p. 3). As condições impostas para o funcionamento dos INCTs foram:

- apoio de médio prazo com recursos substanciais, que poderiam ser convertidos em apoio de longo prazo na dependência do desempenho do instituto e do interesse das fronteiras de financiamento listadas [no programa] ou outras;

- atenção ao equilíbrio entre as regiões do país;

- atuação em áreas estratégicas (induzidas) e em áreas da fronteira da ciência induzidas e demanda espontânea;

- promover pesquisa competitiva e relevante para o país;

- formar recursos humanos especializados;

- forte interação com o sistema produtivo e com a sociedade;contribuir para a consolidação de grupos de pesquisa em novos campi universitários e/ou regiões menos favorecidas (PROGRAMA..., 2008, p. 4).

O processo de seleção para o Programa INCTs contemplou a formação de uma comissão de avaliação de elevada competência responsável pela elaboração do edital estruturado e da carta convite, instrumentos elaborados para esta atividade. A comissão de avaliação e acompanhamento do Programa foi nomeada pelo Ministro de Estado da Ciência e Tecnologia e a operacionalização do Programa foi realizada pelas instituições anteriormente citadas: "CNPq, Capes, Ministério da Saúde, BNDES, e Petrobrás, na esfera federal, FAPEMIG, FAPERJ e FAPESP, nos estados do sudeste e outras entidades financiadoras, dentro de suas modalidades de operação.” (PROGRAMA..., 2008, p. 4).

Os INCTs contemplados deveriam atender a um programa de pesquisa científica ou tecnológica, com um tema de atuação claramente definido o qual deveria ser bem estruturado e permitir "avanços científicos substanciais ou desenvolvimento tecnológico inovador". Não deveria ser apenas um projeto de pesquisa ou um conjunto de projetos de pesquisas, mesmo que eles fossem aparentemente vinculados (PROGRAMA..., 2008, p. 4).

O cumprimento de metas quantitativas e qualitativas foi a intenção do Programa INCT. São três as missões básicas por eles englobadas na primeira edição: 
pesquisa, formação de recursos humanos e transferência de conhecimento para a sociedade. Aos institutos voltados a aplicações na Ciência, Tecnologia e Inovação deve ser adicionada a quarta missão, de transferência de conhecimentos para o setor empresarial ou para o governo. Os elementos compreendidos por estas missões são a seguir detalhados e permitem vislumbrar a ousadia e abrangência do projeto implementado:

Pesquisa. Promoção de pesquisa de vanguarda e elevada qualidade, de padrão competitivo internacionalmente na área de conhecimento. $\mathrm{O}$ centro deve ser estruturado e funcionar como uma referência de excelência nacional na sua área de atuação, de modo a contribuir efetivamente para o desenvolvimento nacional segundo as metas definidas no Plano Nacional de Ciência, Tecnologia e Inovação para o Desenvolvimento Nacional.

Formação de Recursos Humanos. O Instituto deve promover a formação de pessoal qualificado, por meio de cursos de pós-graduação, treinamento pós-doutorado e por meio de envolvimento de estudantes de graduação. Para aqueles institutos voltados a aplicações, tecnologia e relações com empresas, espera-se, além da formação de cientistas acadêmicos de nível internacional, que haja treinamento em ambiente empresarial, cursos de curta e longa duração, treinamento de técnicos especializados, entre outros. Para os institutos voltados à ciência básica e fundamental espera-se a formação de cientistas com inserção internacional e com impacto na criação de ciência e em sua difusão.

Transferência de conhecimento para a sociedade, utilizando outros instrumentos além da publicação científica. O centro deve ter um programa ambicioso de educação em ciência e difusão de conhecimento, conduzido por seus pesquisadores e pelos bolsistas a ele vinculado, focalizado no fortalecimento do ensino médio e na educação científica da população em geral.

Transferência de conhecimento para o setor empresarial ou para o governo. Para aqueles voltados a aplicações da ciência, tecnologia e inovação deve haver mecanismos para a interação e sinergia com o setor empresarial, treinamento de pesquisadores e técnicos que possam atuar nas em- 
presas, e iniciativas que facilitem o desenvolvimento conjunto de conhecimento, produtos e processos. Deve apresentar ênfase em todo o ciclo do conhecimento: do desenvolvimento de ideias a produtos comerciais. Sempre que pertinente à sua temática, deve apresentar em sua proposta organizacional ações para além da academia com ênfase em P\&D e transferência de tecnologia e procurar interagir com o Sistema Brasileiro de Tecnologia (Sibratec). Alternativamente, o Instituto poderá apresentar uma proposta que contribua para a formulação de políticas públicas de interesse do estado ou do governo (PROGRAMA..., 2008, p. 5, grifos do autor).

A estrutura dos INCTs compreendeu em seu coletivo, atores e actantes de diversas esferas, as quais foram identificados como os elementos que permitiam o funcionamento dos institutos, e o suporte para o acompanhamento e instrumentalização das atividades. São nomeados como: instituição sede de excelência; conjunto de laboratórios ou grupos externos à sede, associados de outras instituições articuladas na forma de redes científico-tecnológicas; coordenador com um perfil de pesquisador de reconhecida competência nacional e internacional; comitê gestor composto por cinco pesquisadores do projeto e presidido pelo coordenador; e assessores, os advisory board, cientistas de reconhecida competência em sua área de atuação, de preferência do exterior. Esta estrutura é detalhada a seguir, com atribuições pertinentes.

Coordenador: pesquisador de reconhecida competência nacional e internacional na sua área de atuação, pesquisador $1 \mathrm{~A}$ ou $1 \mathrm{~B}$ do $\mathrm{CNPq}$ (ou equivalente) com capacidade para liderar projetos complexos e com vários participantes, e liderança demonstrada por publicações de impacto em revistas científicas, patentes nacionais ou internacionais, e expressivo resultado em orientação de dissertações ou teses e supervisão de pós-doutores;

Gestão: a proposta deverá contemplar a constituição de um comitê gestor, composto por 5 pesquisadores do projeto e presidido pelo coordenador, que deverá aprovar o plano anual de aplicações de recursos do instituto, além de propor as metas anuais de atividades (pesquisa, formação de recursos humanos, transferência de conhecimento) e ava- 
liar a sua execução, aprovando a revisão anual do contrato de gestão [...]. A gestão do instituto, assim como sua coordenação, não se vincula ou se superpõe à administração da entidade que the serve de sede.

Assessores (Advisory board): cada instituto deve sugerir nomes de assessores, cientistas de reconhecida competência na sua área de atuação, de preferência do exterior para funcionarem como consultores, o Comitê de coordenação do Programa [...] escolherá dois nomes, sendo um radicado no exterior. Esses dois consultores devem visitar o instituto anualmente, examinar seu desempenho frente às metas aprovadas pelo comitê gestor do instituto, e emitir parecer por escrito, que servirá de orientação para o instituto.

Sede: uma instituição pública de ensino ou pesquisa consolidada ou instituição privada sem fins lucrativos. Sua participação no programa deverá ser garantida por documento da autoridade maior garantindo uso da estrutura física e participação de pesquisadores e técnicos no desenvolvimento do projeto, oferecendo, quando pertinente, recursos de contrapartida suficientes para o desenvolvimento do projeto;

Laboratórios associados: laboratórios ou grupos de pesquisa externos à sede que se associam para desenvolvimento do projeto, podendo pertencer a instituições públicas, privadas ou empresas. Como no caso da sede, a participação tem que ser autorizada pelo dirigente competente, colocando à disposição do projeto os recursos materiais e humanos necessários. Cada laboratório associado deverá ter um pesquisador responsável (PROGRAMA.., 2008, p. 6, grifo do autor).

A previsão inicial de duração do programa dos INCTs foi de cinco anos; os primeiros três anos teriam o financiamento assegurado e após a avaliação seria concedida a continuidade do apoio aos dois anos restantes. A divisão dos INCTs em três grupos privilegiou as faixas de valores do financiamento e dependiam da necessidade de recursos para execução das propostas. Estas faixas foram classificadas da seguinte forma: 
Faixa A, Institutos envolvidos com atividades que não necessitam de equipamentos ou reagentes de altos custos;

Faixa B, Institutos cujos programas são de natureza experimental, que exigem equipamentos e reagentes de custos baixo e médio; ou

Faixa $C$, Institutos cujos programas são de natureza experimental, que exigem equipamentos e reagentes de alto custo (CNPq, 2008, grifo nosso).

A distribuição dos recursos para as regiões cobertas foi assegurada considerando-se a sede do instituto. As regiões norte, nordeste e centro-oeste obtiveram cerca de 35\% dos recursos, a região sul 15\% e a sudeste 50\% dos recursos (CNPq, 2008).

O Programa INCTs realizou sua primeira avaliação prevista no Edital 15/2008, nos dias 23 e 24 de novembro de 2010, em Brasília, o primeiro balanço das ações desenvolvidas nos últimos dois anos desde o seu lançamento em 2008. O órgão responsável pela coordenação da avaliação foi o Centro de Gestão e Estudos Estratégicos (CGEE), contratado especialmente pelo MCT para participar, junto com o CNPq do trabalho de acompanhamento do programa. O evento foi chamado de I Reunião de Acompanhamento e Avaliação dos INCTs e, a título de incentivo, os institutos que apresentara melhor desempenho conquistaram a prorrogação dos recursos de pesquisa, prevista no Edital 15/2008, por mais 24 meses, além do período regular de três anos (CENTRO DE GESTÃO E ESTUDOS ESTRATÉGICOS, 2010; TORRES, 2010).

A avaliação foi positiva, apesar das dificuldades relatadas pelos coordenadores em questões de gestão e aspectos legais da aplicação dos recursos. Segundo José Carlos Maldonado, coordenador de um dos INCTs avaliados, o Instituto de Ciências Matemáticas e de Computação (ICMC), da USP, "essas dificuldades fazem parte do processo de aprendizagem inerente à implantação dos institutos. Isso é natural porque se trata de um programa inovador, que mudou paradigmas de relações estruturantes e de articulação das instituições científicas no Brasil." (CASTRO, 2010). 
O II Seminário de Acompanhamento e Avaliação dos INCTs foi realizado em Brasília, no período de 02 a 04 de julho de 2013. Nesse evento, foi anunciado pelo então ministro da Ciência, Tecnologia e Inovação, Marco Antonio Rauppo, a continuidade do financiamento ao Programa Institutos Nacionais de Ciência e Tecnologia, renovação dos contratos e mudança do sítio oficial. A previsão de lançamento do novo edital foi anunciada para o período de outubro a novembro de 2013, com avaliações previstas entre fevereiro e setembro de 2014 (CNPq, 2013a).

Entretanto, apesar do lançamento do edital e recebimento das propostas no período de 7 de julho a 8 de setembro de 2014, o resultado da Chamada INCT MCTI/CNPQ/CAPES/FAPS N ${ }^{\circ}$ 16/2014 (CNPq, 2014a) previsto para sair a partir de 6 de março de 2015, somente foi divulgado em 11 de maio de 2016. Do total de 345 propostas submetidas, 115 eram de INCTs já existentes e 230 para criação de novos institutos. O resultado contemplou 252 propostas, as quais receberam recomendação no processo de análise de mérito técnico-científico para financiamento. Os recursos de contestação do resultado da chamada somente poderão ser realizados a partir de 11 de julho de 2016, dois meses após a divulgação do resultado (CNPq, 2016a). 